\title{
Particle breakage in gap-graded soil
}

\author{
X. ZHANG* and B. A. BAUDET*
}

\begin{abstract}
One-dimensional compression tests to high stresses were performed on gap-graded soil specimens in order to investigate their breakage behaviour. Gap-graded specimens were produced by combining small and large soil particles with ratios of large to small grain diameters varying between 5 and 15, and with varying proportions of small grains. Breakage was observed as the particle size distribution evolved with stress level. It was found that, unlike most soils and in contrast to what is usually assumed, the gap-graded specimens did not tend towards a fractal grading curve. Instead, the particular shape of their initial grading curve constrained the organisation of the breakage. The ratio between large and small grain diameters does not seem to affect the amount of small grains created or the relative breakage. A fractal dimension could still be computed from the number of particles, and it was found to increase slightly with small grains content. Finally, it was observed that the shape of particles does not change upon breakage.
\end{abstract}

KEYWORDS: fractals; particle crushing/crushability; particle-scale behaviour; sands

ICE Publishing: all rights reserved

\section{INTRODUCTION}

Granular soils are generally found to be crushable, so that their particles break into smaller sized particles under large stress or strain (e.g. Lee \& Farhoomad, 1967; Nakata et al., 1999; Coop et al., 2004). Glaciologists have long assumed that, eventually, a sediment would reach an ultimate grading (e.g. Sammis et al., 1987), a concept that has been adopted more recently in the geotechnical community. For example, Muir Wood (2006) proposed a grading index to describe the evolution of the particle size distribution of a crushable soil during loading, which uses limiting, fractal grading as a boundary to possible grading states. The ultimate fractal grading is then characterised by a linear distribution in a typical grading graph plotted using logarithm axes, the fractal dimension of the grain assembly being equal to three minus the slope of that line. Einav (2007a) also formulated the idea of an ultimate grading as a tool to quantify the breakage of a soil. These theories were founded on published evidence that the breakage in granular soils appears to stop at very large strains or stresses (Coop et al., 2004), evidence that had not been previously found (e.g. Lee \& Seed, 1967). The ultimate grading may not be unique for a given soil, but may depend on the initial size of grains or the confining stress for breakage achieved through shearing (Coop et al., 2004). For some soils that have a very well graded particle size distribution, such as glacial soils, their in situ grading might not evolve when subjected to high strain or stress (Altuhafi et al., 2011). This is corroborated by the results of onedimensional (1D) compression tests to large stresses on specimens of sand artificially created to be graded with a fractal distribution of particles (Altuhafi \& Coop, 2011). Gap-graded soils do not fall into the category of either poorly graded or well graded soils, and they may not reach an ultimate grading that is fractal, but 'an alternative ultimate grain size distribution will evolve, following a different path of organization' (Einav, 2007b). This paper presents experimental data on the breakage of gap-graded

Manuscript received 4 March 2013; first decision 2 May 2013; accepted 30 May 2013.

${ }^{*}$ The University of Hong Kong, Hong Kong soils during $1 \mathrm{D}$ compression that may bring additional substance to the above debate.

\section{MATERIALS AND TESTING PROCEDURES}

This study focused on the 1D compression behaviour of gap-graded soils created artificially by combining small and large soil particles in different proportions. The soil used was completely decomposed granite (CDG), which is the product of Hong Kong granitic rocks that have weathered into soil particles ranging in size from coarse sand to silt, the latter often being attached to the sand particles. The mineralogy of the soil grains consists predominantly of quartz and feldspar. The natural CDG was washed with great care to remove fines from the surface of the coarse particles; it was then manually dry sieved into its constituent size ranges. Different sizes of grains were selected from the coarse range $(0 \cdot 063-0 \cdot 15,0 \cdot 15-0 \cdot 212$, $0 \cdot 212-0 \cdot 3,0 \cdot 6-1 \cdot 18,1 \cdot 18-2$ and $2-2 \cdot 36 \mathrm{~mm}$ ) with a ratio $(R)$ of large to small particle diameters varying between 5 and 15. Both small and large particles are potentially crushable under stress or strain. Because the smaller particles were larger than silt size, they are referred to here as small grains (SG) content rather than fines content, which would not be strictly correct. Each specimen was prepared at a designed initial grading by mixing small and large particles in exact proportions from 20 to $60 \%$ SG content.

Oedometer tests were carried out up to medium to high pressures on the artificially gap-graded specimens. The specimens were prepared by moist tamping with $0.5 \%$ water content to ensure that the small and large grains were homogeneously distributed and did not segregate. For each SG content, dense and loose samples were prepared. The specimens were saturated and compressed up to $31 \mathrm{MPa}$ vertical stress in a specially designed $20 \mathrm{~mm}$ diameter oedometer cell. The consolidation cell was filled with water. In order to ensure saturation in these small specimens where the degree of saturation could be measured accurately, the specimens were soaked for approximately $10 \mathrm{~h}$ prior to testing. The initial global void ratio of the specimen was calculated using three different methods 
relying on independent measurements (the initial dry weight and dimensions measured by caliper and from the initial reading of the dial gauge, as well as back-calculated from the final height of specimen and the vertical deformation). It was verified that the void ratios calculated by the three methods were within $\pm 0 \cdot 01$. The final grading was estimated after each test by mechanical dry sieving. Table 1 summarises the tests performed.

\section{TEST RESULTS}

One-dimensional compression tests were performed on specimens with ratios of large to small particle diameters $R$ equal to $5,8 \cdot 5,12$ and 15 , for various initial SG contents. For each test, particular attention was given to the accuracy of the determination of the initial void ratio so that non-convergence between lines could not be due to error in computing the void ratio. The $1 \mathrm{D}$ normal compression lines for specimens prepared with 20, 40 and $60 \%$ initial SG content are shown in Fig. 1. It seems that, as the proportion of SG increases, the lines may not converge at $31 \mathrm{MPa}$; this is particularly evident in the 60\% SG content specimens (Fig. 1(c)). The uniqueness of the normal compression line in granular soils has been attributed to the breakage of soil grains (Coop \& Lee, 1993; McDowell \& Bolton, 1998), therefore it is anticipated that at large SG contents the breakage is not sufficient to reach a unique line. Altuhafi \& Coop (2011) also found that the normal compression curves of well graded soil specimens did not converge.

Some tests were also carried out at intermediate stresses of 12 and $25 \mathrm{MPa}$ on specimens prepared at $R=8 \cdot 5$, and the particle size distribution of the specimens was determined after the tests. Figure 2 shows the grading curves at 12 and $25 \mathrm{MPa}$; in each case the test was repeated to verify the results. The grading curves evolve with stress level, around a pivot for $100 \%$ passing the large grain size of $2.36 \mathrm{~mm}$, and a pivot or 'knee' determined by the SG content. For both 30 and $50 \%$ SG content there is no tendency to depart from the bi-modal aspect of the grading to reach a unique, smooth particle size distribution.

Tests were carried out over a range of SG contents from 0 to $60 \%$, with $R=12$ and $R=5$. The pivot that occurs either at or slightly above the 'knee' representing the size of the small grains in the specimens before testing is seen for all SG contents except $0 \%$ (Fig. 3). The grading curve representing a fractal particle size distribution of dimension $D=2 \cdot 5$ is shown as a thick black line. This fractal dimension of 2.5 is the dimension found to correspond to the ultimate grading of granular assemblies subjected to $1 \mathrm{D}$ compression (McDowell \& Bolton, 1998; Einav, 2007a). The particle size distribution of a poorly graded specimen constituted solely of coarse particles (e.g. BFC00 in Fig. 3(b)) tends to evolve towards the fractal grading as

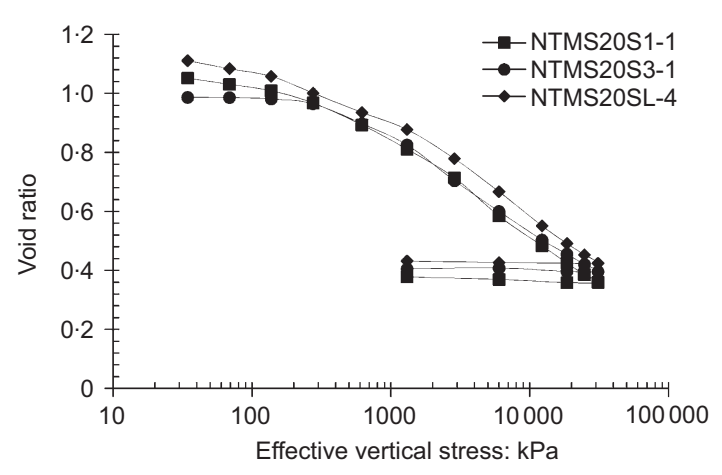

(a)

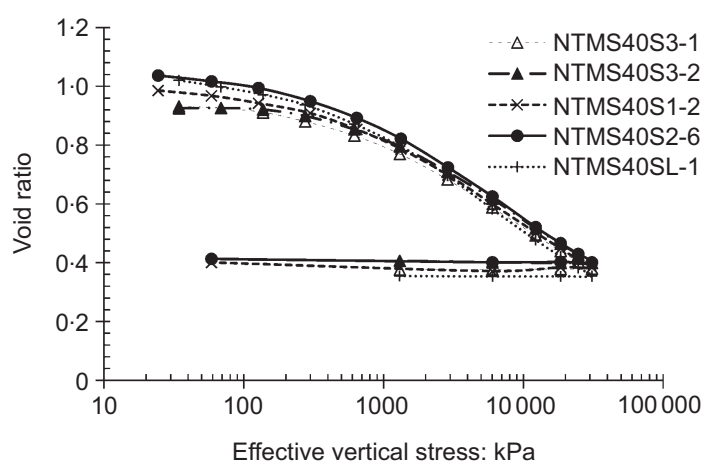

(b)

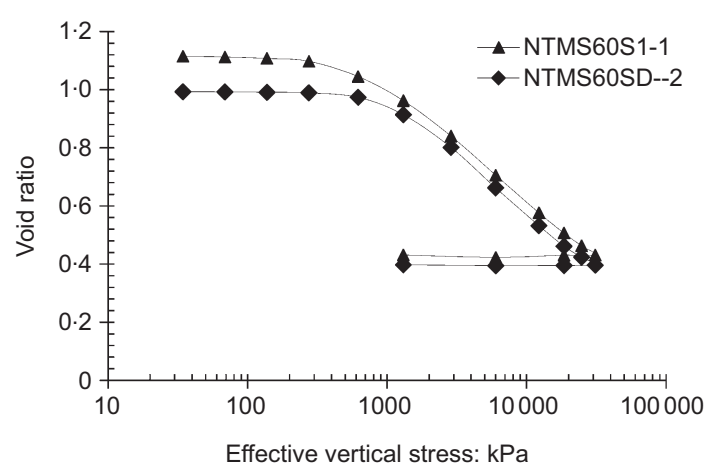

(c)

Fig. 1. One-dimensional normal compression line for $R=12$ at initial SG content of (a) $20 \%$, (b) $40 \%$ and (c) $60 \%$

the pressure increases. This has also been observed previously by other researchers, on a variety of soils (e.g. Coop \& Lee, 1993; Nakata et al., 1999; Coop et al., 2004).

When the gap between large and small particle sizes is narrow $(R=5$, Fig. 3(b)), the gradings of the gap-graded specimens for SG contents up to $40 \%$ all plot below the fractal grading. In this case, the pivot only becomes clear at

Table 1. Test details (several tests were repeated, denoted $\times \ldots$ )

\begin{tabular}{l|c|c|l|c}
\hline Series & $R\left(d_{\text {large }} / d_{\text {small }}\right)$ & Large grain size: mm & \multicolumn{1}{|c}{ Initial SG content: $\%$} & $\begin{array}{c}\text { Maximum vertical } \\
\text { stress: MPa }\end{array}$ \\
\hline BFC & 5 & $0 \cdot 60-1 \cdot 18$ & $0,20,30,40,60$ & 31 \\
TM & $8 \cdot 5$ & $2 \cdot 00-2 \cdot 36$ & $30(\times 4), 50(\times 3)$ & $12(\times 3), 25(\times 2)$ \\
TMS & $8 \cdot 5$ & $2 \cdot 00-2 \cdot 36$ & $20(\times 2), 30,40,50,60$ & 25 \\
NTMS & 12 & $2 \cdot 00-2 \cdot 36$ & $20(\times 3), 30(\times 2), 40(\times 3), 50$, & 31 \\
AFC & 15 & $1 \cdot 18-2 \cdot 00$ & $60(\times 2)$ & 31 \\
\hline
\end{tabular}

${ }^{\mathrm{a}}$ Tests performed dry 


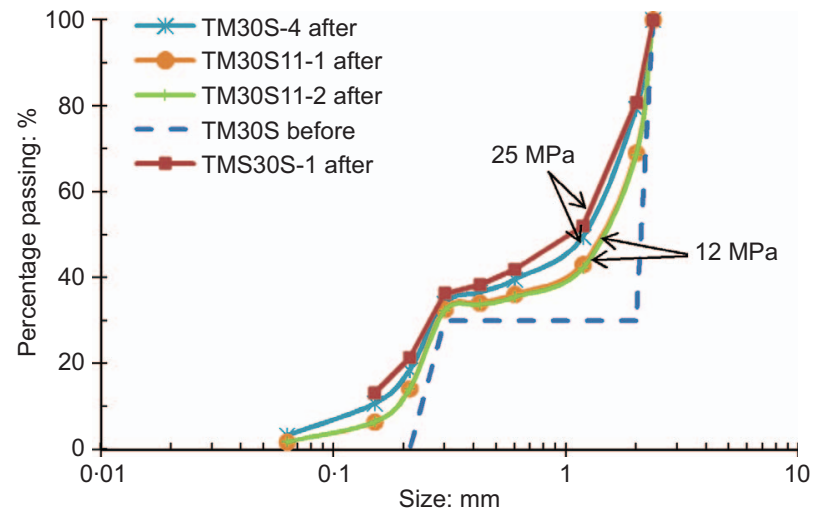

(a)

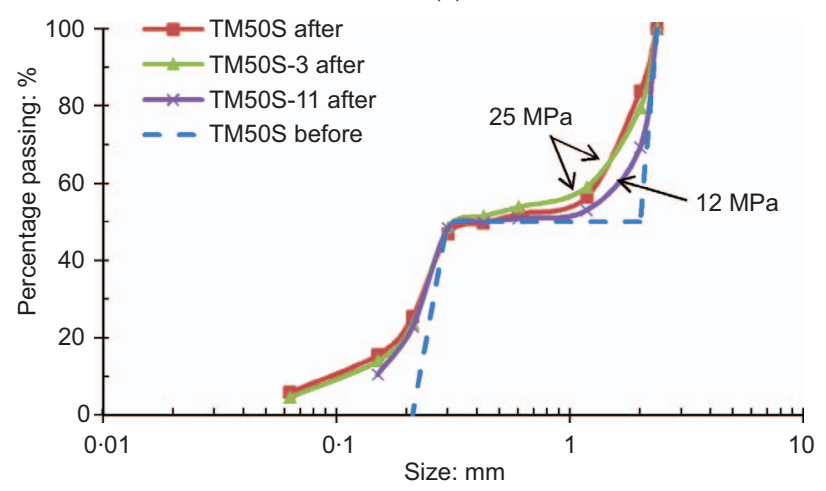

(b)

Fig. 2. Evolution of particle size distribution with vertical effective stress for $R=8.5$ at initial SG content of (a) $30 \%$ and (b) $50 \%$

$40 \%$ SG content. For a larger gap in sizes $(R=12$, Fig. 3(a)), some of the gradings of the gap-graded specimens plot above the fractal grading. One can assume that for these initial particle size distributions it is not possible to reach the ultimate fractal grading of $D=2 \cdot 5$.

Figure 4 shows a schematic diagram of the relative positions of gap-graded particle size distributions and a fractal grading of dimension $D=2 \cdot 5$, for $R=5$ and $R=$ 12. For $R=5$, the knee of the gap-graded particle size distribution touches the fractal grading curve at 30\% SG content while, for $R=12$, this occurs at $42 \% \mathrm{SG}$ content. For SG contents above those values, the grading curve evolves with a pivot at the knee during compression. The SG fraction then tends towards a fractal distribution of particles from the knee, while the large grains fraction is constrained by the knee. Additional evidence was found by dyeing some large particles black before one test: fragments of these particles were found in large quantities in the larger sizes of grains, while none were found in the smaller grain sizes.

From Fig. 4 it is anticipated that, above the threshold values of 30 and $42 \%$ for $R=5$ and $R=12$ (in this example), there should be no creation of small grains. The proportion of small grains created during compression is plotted against small grain content for different $R$ values in Fig. 5. This is calculated as the difference in percentage passing the small grain size sieve $(0 \cdot 15,0 \cdot 212$ or $0.3 \mathrm{~mm}$ depending on the test) before and after compression. The amount of small grains created decreases with increasing SG content, similarly to the observations of Sammis \& Stacey (1995) on bi-sized assemblies of spheres of 1.5 and $3 \mathrm{~mm}$. The data for 50 and $60 \%$ SG content are not shown

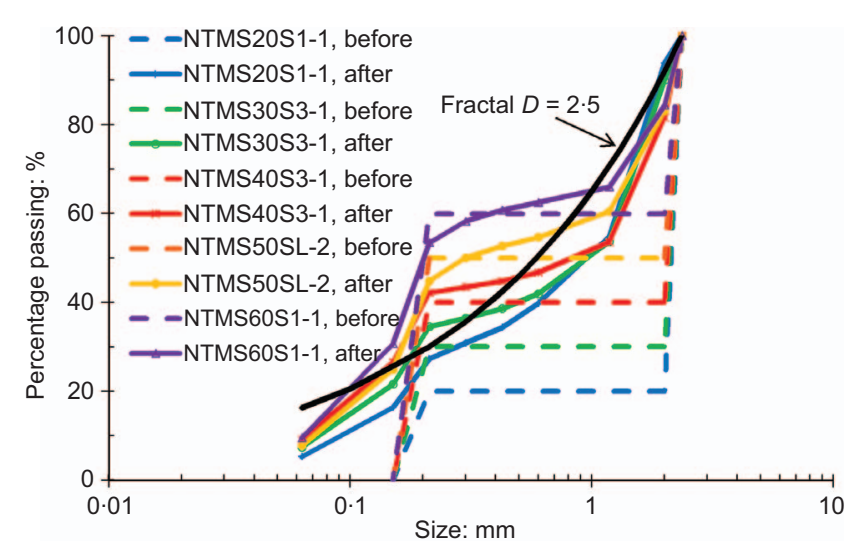

(a)

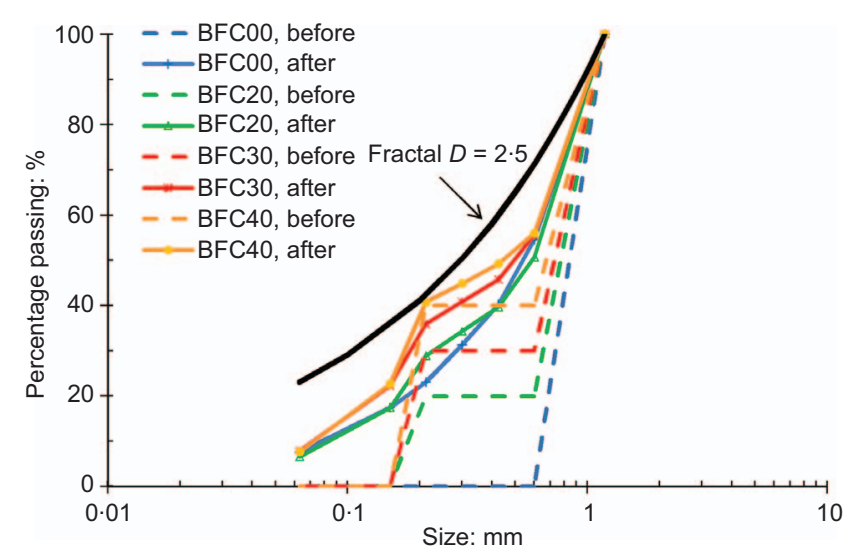

(b)

Fig. 3. Particle size distributions before and after compression to $31 \mathrm{MPa}$ for (a) $R=12$ and (b) $R=5$

as it was found from sieving that their SG content decreased slightly; this can only be an error, perhaps due to the agglomeration of very small particles onto larger ones. It is interesting to note that the data fit within a narrow band, irrespective of the ratio $R$. This is not in agreement with Fig. 4, in which the point where the knee touches the fractal grading, which might be expected to be a threshold point of no SG creation, should vary with $R$. The amount of small grains created at the stresses reached here is about half that calculated from the vertical distance between the knee and the fractal grading (Fig. 6).

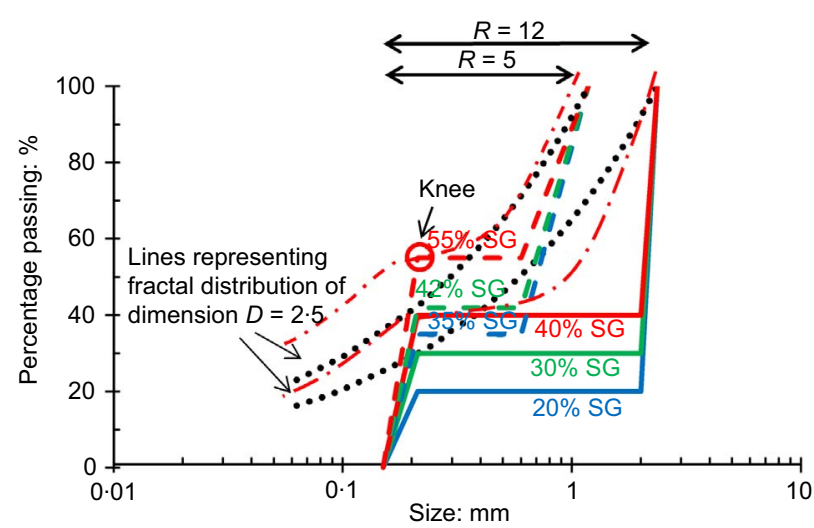

Fig. 4. Schematic diagram representing the relative positions of the gap-graded and fractal particle size distributions for different ratios of large to small grain diameters 


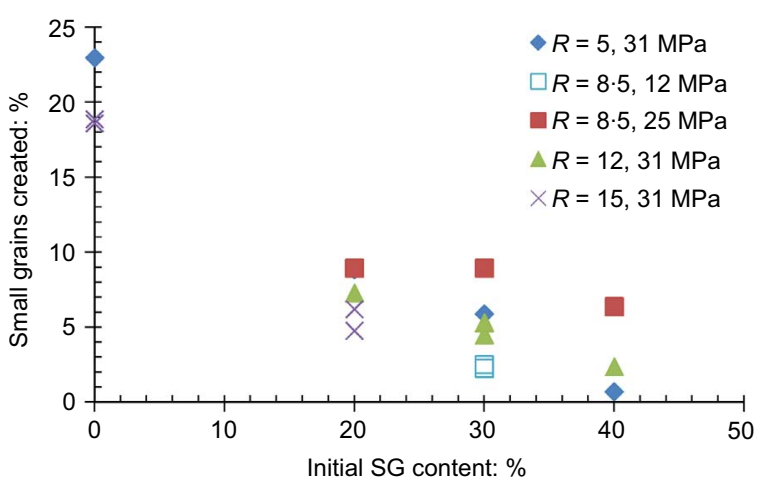

Fig. 5. Variation in quantity of small grains created with initial $S G$ content for different stress levels and ratio of large to small grain diameter $R$

Figure 7 reports the overall amount of breakage in the specimens after compression to 12,25 and $31 \mathrm{MPa}$. The total, potential and relative breakages were computed using the method proposed by Hardin (1985) - the total breakage is the area between the initial and final grading curves, the breakage potential is calculated assuming all particles had broken to become smaller than $63 \mu \mathrm{m}(63 \mu \mathrm{m}$ was used here due to sieve availability instead of $74 \mu \mathrm{m}$ recommended by Hardin (1985)) and the relative breakage is the ratio of total breakage to the breakage potential. This method was considered preferable to Einav's method, which uses the ultimate grading curve in computation of the breakage (Einav, 2007a), and therefore is not applicable to gapgraded soils.

Total, potential and relative breakages decrease with increasing SG content, which is expected since the number of particle contacts increases with increasing initial SG content. For a given ratio $R$, the breakage increases with stress level but, at a given stress level, it seems that not only the ratio $R$ but also the size of the larger grains of the assembly influences the breakage. For example, at the given stress level of $31 \mathrm{MPa}$, there is much more breakage in specimens with $R=12$ than with $R=5$; however, for $R=$ 15 , the total and relative breakage lies between the two. On the other hand, noting that the total and relative breakage of $R=8 \cdot 5$ and $R=12$ are similar at high stresses of 25 and $31 \mathrm{MPa}$, the difference in patterns between $R=12$ and $R$ $=15$ must stem from the fact that their large particles were of very different size. In fact, referring to Table 1 , the breakage seems to increase with the size of the large particles. For a small ratio of large to small particle

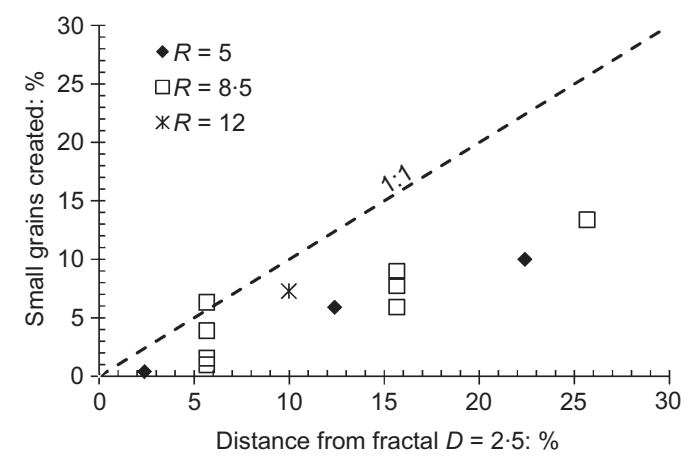

Fig. 6. Dependence of SG content for no creation of small grains on ratio of large to small grain diameter $R$

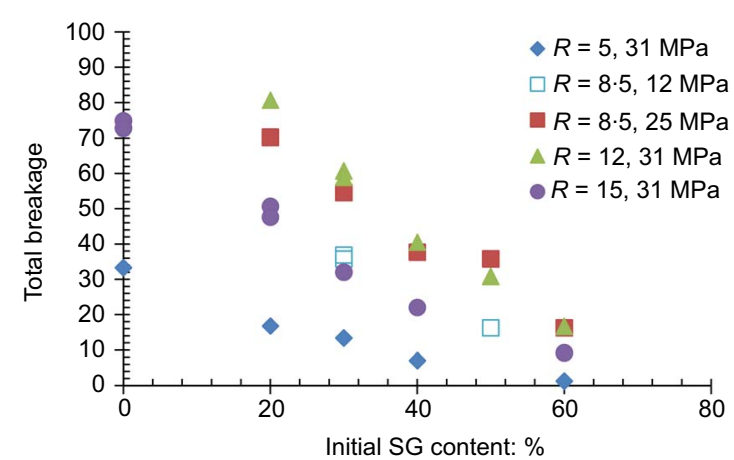

(a)

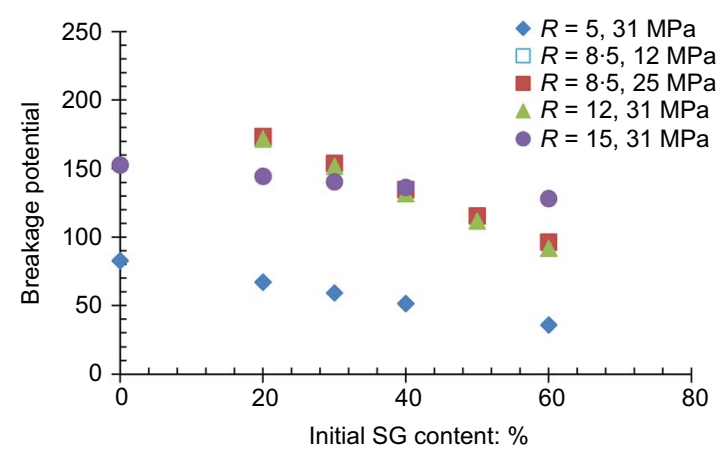

(b)

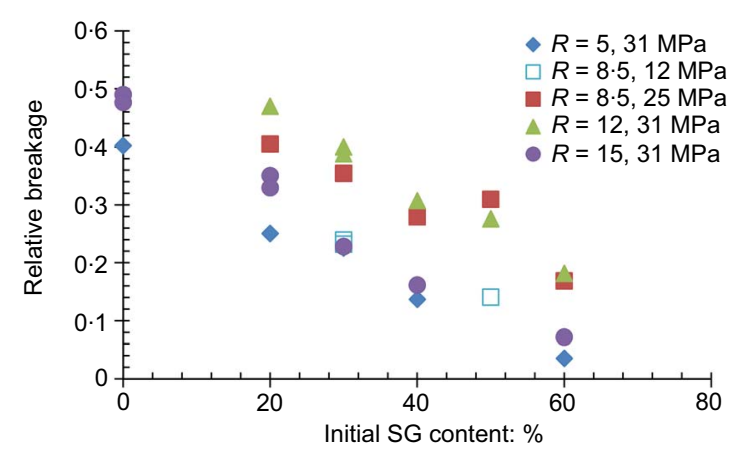

(c)

Fig. 7. Variation of (a) total breakage, (b) breakage potential and (c) relative breakage with initial SG content for different stress levels and ratio of large to small grain diameter $R$

diameters $R$, the small grains may participate in the contact force chain, thus reducing the amount of stress on the larger grains; for large ratios, the small grains may not participate in the contact force chain, leaving the larger grains under larger stresses and more vulnerable to breaking. This was found by Vallejo et al. (2005) while Vallejo \& Lobo-Guerrero (2012), based on results using the discrete element method, showed that in bi-sized mixtures subjected to compression the larger particles develop the highest intensity force chains and tend to break. Thevanayagam (2000) suggested that a ratio above 6.5 is necessary for the latter scenario.

Since it was not possible to determine a fractal dimension from the particle size distributions in Fig. 3, the definition of fractal dimension $D$ proposed by Mandelbrot (1982) was used, where $D$ is given as the gradient in a double logarithmic plot of number of particles against particle size. Turcotte (1986) proposed that there is a relationship between the total number of particles and particle size $d$ greater than $x$ such that

$$
N(d \geq x) \propto x^{-D}
$$


It is posed here that the number of particles of size larger than $d$ can be expressed as

$$
N(d)=N_{0}\left(\frac{d}{d_{0}}\right)^{-D}
$$

where $N_{0}$ is the number of particles of reference size $d_{0}$. Following the approach of Hooke \& Iverson (1995), it is assumed that the soil particles are spherical, so the weight of particles between sizes $d_{1}$ and $d_{2}$ is

$$
\begin{aligned}
W\left(d_{1}, d_{2}\right) & =\int_{d_{2}}^{d_{1}} \rho \frac{\pi}{6} d^{3} \frac{\mathrm{d} N(d)}{\mathrm{d}(d)} \mathrm{d}(d) \\
& =\frac{\pi}{6} \rho N_{0} d_{0}^{D}(-D) \frac{d_{1}^{3-D}-d_{2}^{3-D}}{3-D}
\end{aligned}
$$

The weight is calculated by integrating from $d_{2}$ to $d_{1}$ because the total number of large particles $\left(d_{1}\right)$ is smaller than that of small particles $\left(d_{2}\right)$. The number of particles between sizes $d_{1}$ and $d_{2}$ is

$$
\begin{aligned}
N\left(d_{1}, d_{2}\right) & =\int_{d_{2}}^{d} \frac{\mathrm{d} N(d)}{\mathrm{d}(d)} \mathrm{d}(d) \\
& =\int_{d_{2}}^{d_{1}} N_{0} d_{0}^{D}(-D) d^{-D-1} \mathrm{~d}(d) \\
& =N_{0} d_{0}^{D}\left(d_{1}^{-D}-d_{2}^{-D}\right)
\end{aligned}
$$

Substituting equation (3) into equation (4) yields

$$
N\left(d_{1}, d_{2}\right)=\frac{6 W\left(d_{1}, d_{2}\right)(D-3)}{\rho \pi D} \frac{d_{1}^{-D}-d_{2}^{-D}}{d_{1}^{3-D}-d_{2}^{3-D}}
$$

The mean size in the interval is given by

$$
d_{\text {mean }}=\left(\frac{6 W\left(d_{1}, d_{2}\right)}{N\left(d_{1}, d_{2}\right) \pi \rho}\right)^{1 / 3}
$$

By trial and error, a value of $D$ can be found for which the best curve fitting of the plot of $N\left(d_{1}, d_{2}\right)$ against $d_{\text {mean }}$ can be found. Figure 8 shows the results for all specimens, with linear trends for each initial SG content. It is clear from the figure that the regression is better in the small grains fraction, and again for large particles, but in between the agreement is poorer. It must be noted that a soil may reach an ultimate grading for which no more breakage occurs that is not necessarily fractal. The points for sizes between

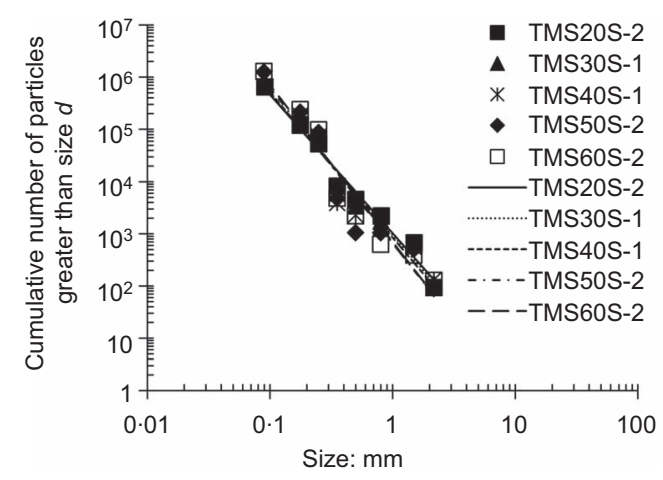

Fig. 8. Determination of fractal number as slope of the number of particles against particle size; the data points are for all data from compression tests to $25 \mathrm{MPa}$ the two initial sizes correspond to the organisation of particles constrained at the knee. The fractal dimensions computed from Fig. 8 are plotted against SG content in Fig. 9. There is a slight increase in fractal dimension as the initial SG content increases, independently of the ratio $R$ when the initial SG content is larger than $40 \%$. The fractal dimension tends to a value of 3 at $60 \%$ SG content - a similar value to that found for glacial soils (e.g. Altuhafi \& Baudet, 2011).

The shapes of the grains for one specimen prepared with $40 \%$ SG content were determined using a particle image analyser able to measure particle sizes between $1 \mu \mathrm{m}$ and $20 \mathrm{~mm}$. A flow of randomly orientated, moving particles falling from a dry gravity feeding system (particles between 0.05 and $200 \mathrm{~mm}$ diameter) or circulating through a water system (particles less than $63 \mu \mathrm{m}$ in this study) can be examined by dynamic image analysis. The size and shape of each particle can be evaluated from its image; here, the aspect ratio between smallest and largest measured dimension across the particle was used to monitor the shape before and after testing. Figure 10 plots the variation in aspect ratio with particle size before and after testing for two samples (no. 1 and no. 2) of the same specimen. In agreement with the findings of Altuhafi \& Coop (2011) on particles of similar aspect ratio (larger than 0.60), breakage did not induce a significant change in particle shape. The large particles fragment into smaller particles of similar shape.

\section{CONCLUSIONS}

Gap-graded specimens comprising large and small grains with ratios of sizes varying between 5 and 15, and with varying proportions of small grains, were tested to high pressures under 1D compression. The following results were obtained.

- Gap-graded specimens with ratios of large to small grain diameters between 5 and 15 do not tend towards an ultimate fractal particle size distribution when their small grains (SG) content is more than $20 \%$.

- The particle size distribution instead evolves as a bimodal curve with a pivot at the 'knee' of the initial grading curve. Preliminary results not shown here and using a ring shear apparatus seem to indicate that the bimodal curve also remains upon intense shearing.

- The amount of small particles created during compression seems to depend on the SG content but not on the ratio of large to small grain diameters.

- The amount of breakage seems to depend on the size of the larger particles in the assembly more than the ratio of large to small grain diameter.

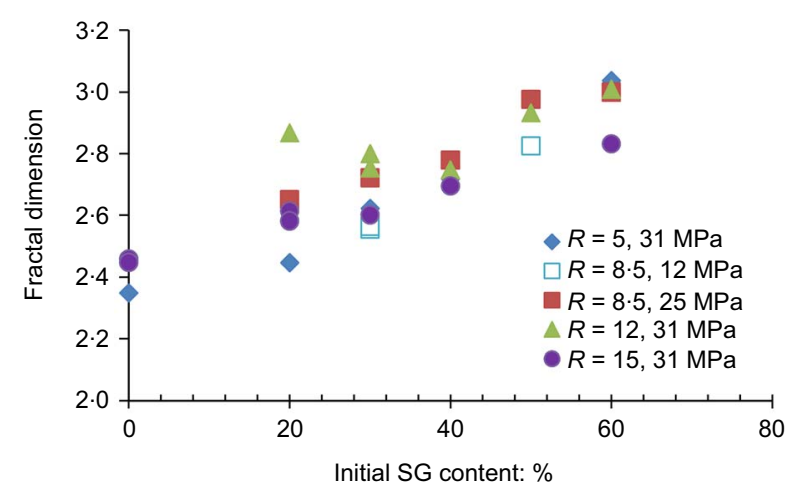

Fig. 9. Variation of fractal dimension with initial SG content 


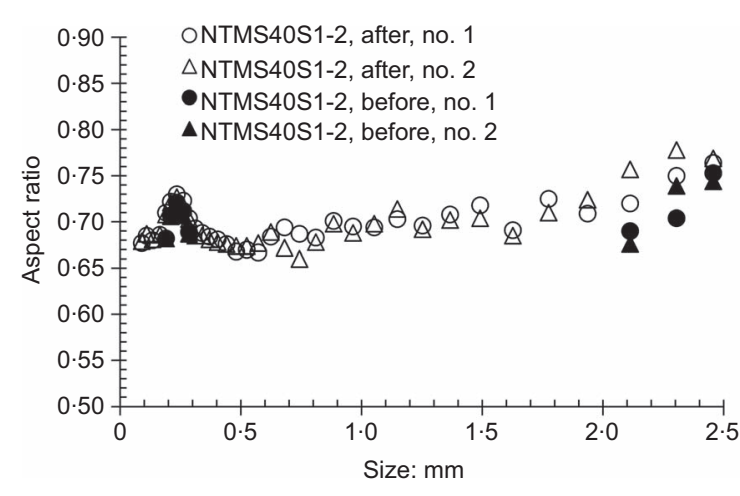

Fig. 10. Evolution of aspect ratio of particles during test for a specimen with $40 \%$ SG content compressed to $31 \mathrm{MPa}$

- The fractal dimension, computed using the number of particles, varies slightly with initial SG content.

- The shape of the particles does not change with breakage upon 1D compression for these common particles of initial aspect ratio larger than $0 \cdot 60$.

\section{Acknowledgements}

The authors are grateful to the University Development Fund of The University of Hong Kong for facilitating the purchase of the particle image analyser and the University Grants Council and Department of Civil Engineering for funding the research. The authors also heartedly thank Miss Kai Ling Yip for carrying out some of the tests and Professor Matthew Coop for his very useful advice.

\section{REFERENCES}

Altuhafi, F. \& Baudet, B. A. (2011). A hypothesis on the relative roles of crushing and abrasion in the mechanical genesis of a glacial sediment. Engng Geol. 120, No. 1, 1-9.

Altuhafi, F. \& Coop, M. R. (2011). Changes to particle characteristics associated with the compression of sands. Géotechnique 61, No. 6, 459-471.

Altuhafi, F., Baudet, B. A. \& Sammonds, P. (2011). On the particle size distribution of a basaltic till. Soils Found. 51, No. $1,113-121$.

Coop, M. R. \& Lee, I. K. (1993). The behaviour of granular soils at elevated stresses. In: Predictive soil mechanics. Proc. C. P. Wroth memorial symposium. London: Thomas Telford, pp. 186-198.

Coop, M. R., Sorensen, K., Bodas deFreitas, T. \& Georgoutsos, G. D. (2004). Particle breakage during shearing of carbonate sand. Géotechnique 54, No. 3, 157-163.

Einav, I. (2007a). Breakage mechanics - part I: theory. J. Mech. Phys. Solids 55, 1274-1297.

Einav, I. (2007b). Fracture propagation in brittle granular matter. Proc. R. Soc. A 463, 3021-3035.

Hardin, B. O. (1985). Crushing of soil particles. J. Geotech. Engng ASCE 111, No. 10, 1177-1192.

Hooke, R. LeB. \& Iverson, N. R. (1995). Grain size distribution in deforming subglacial tills: role of grain fracture. Geology 23, 57-60.

Lee, K. L. \& Farhoomad, I. (1967). Compressibility and crushing of granular soil in anisotropic triaxial compression. Can. Geotech. J. 4, No. 1, 68-86.

Lee, K. L. \& Seed, H. B. (1967). Drained strength characteristics of sands. J. Soil Mech. Found. Div. ASCE 93, No. 6, 117-141.

Mandelbrot, B. B. (1982). The fractal geometry of nature. New York: W. H. Freeman.

McDowell, G. R. \& Bolton, M. D. (1998). On the micro-mechanics of crushable aggregates. Géotechnique 48, No. 5, 667-679.

Muir Wood, D. (2006). Geomaterials with changing grading: a route towards modelling. In Geomechanics and geotechnics of particulate media (Hyodo, M. \& Nakata, Y. (eds)). London: Taylor \& Francis, pp. 313-325.

Nakata, Y., Hyde, A. F. L., Hyodo, M. \& Murata, H. (1999). A probabilistic approach to sand crushing in the triaxial test. Géotechnique 49, No. 5, 567-583.

Sammis, C. G. \& Stacey, S. J. (1995). Fractal fragmentation in crustal shear zones. In Fractals in the earth sciences (Barton, C. C. \& La Pointe, P. R. (eds)). New York: Plenum Press, pp. 179-204.

Sammis, C., King, G. \& Biegel, R. (1987). The kinematics of gouge deformation. Pure Appl. Geophys. 125, 777-812.

Thevanayagam, S. (2000). Liquefaction potential and undrained fragility of silty soils. Proc. 12th World Conf. on Earthquake Engineering, Auckland, New Zealand, p. 8.

Turcotte, D. L. (1986). Fractals and fragmentation. J. Geophys. Res. 91, No. B2, 1921-1926.

Vallejo, L. E. \& Lobo-Guerrero, S. (2012). The shear strength of granular materials containing dispersed oversized particles: DEM analysis. Int. J. Geotech. Engng 6, No. 3, 371-380.

Vallejo, L. E, Lobo-Guerrero, S. and Chik, Z. (2005). A network of fractal force chains and their effect in granular materials under compression. In Fractals in engineering: new trends in theory and applications (Levy-Vehel, J. \& Lutton, E. (eds)). London: Springer Verlag, pp. 67-80.

\section{WHAT DO YOU THINK?}

To discuss this paper, please email up to 500 words to the editor at journals@ice.org.uk. Your contribution will be forwarded to the author(s) for a reply and, if considered appropriate by the editorial panel, will be published as a discussion. 